\title{
Development of polymorphic microsatellite markers and the population genetic structure of the half-fin anchovy, Setipinna taty
}

\author{
Y.N. Sun, Y. Qin, Z.H. Zhu and D.Q. Sun \\ Laboratory of Fish Biogenetics and Immune Evolution, \\ College of Marine Science, Zhejiang Ocean University, Zhoushan, China \\ Corresponding author: Y.N. Sun \\ E-mail: yuenasun@163.com
}

Genet. Mol. Res. 13 (3): 6293-6302 (2014)

Received March 27, 2013

Accepted August 27, 2013

Published April 3, 2014

DOI http://dx.doi.org/10.4238/2014.April.3.1

\begin{abstract}
Microsatellite markers for the half-fin anchovy Setipinna taty were developed from the enriched $(\mathrm{CA})_{15}$ genomic library, and they were used for the population genetic studies of the half-fin anchovy from Chinese coastal areas. Samples were collected from five localities of the East China Sea and the Yellow Sea. Eleven simple sequence repeat markers were used to assess genetic differentiation in 30 individuals at each locality. As a result, 59 alleles were recorded over all loci with an average of 5.36 alleles per locus. Observed and expected heterozygosities ranged from 0.27 to 0.73 and 0.50 to 0.89 , respectively. Analysis of molecular variation indicated that the variation within individuals was high $(70.68 \%)$, while variations of individuals within and among populations were low (22.47 and 6.85\%). The phylogenetic tree showed that these populations could be divided into two clusters: populations of the East China Sea, which came from Ninghai, Xiangshan and Zhoushan, and populations of the Yellow Sea, which were from Yantai and Weihai. It revealed that significant geographic structure existed in this species. All of the results indicated that high genetic diversity existed in the half-fin anchovy from different
\end{abstract}


geographic populations. This conclusion was consistent with the classification based on morphological and physiological characteristics.

Key words: Population genetic structure; Genetic diversity; Microsatellite markers; Setipinna taty

\section{INTRODUCTION}

The half-fin anchovy, Setipinna taty (Clupeiformes, Engraulidae), which is a commercially important near-shore species, is widely distributed in the Indian Ocean, the western Atlantic Ocean, and all of the coastal areas of China. Generally, the half-fin anchovy attains an average length of $15 \mathrm{~cm}$ and weight of $25 \mathrm{~g}$. It inhabits shallow seas with a depth around 4-5 m. The optimal living temperature ranges from $5^{\circ}$ to $28^{\circ} \mathrm{C}$. The half-fin anchovy feeds on plankton and crustaceans (Gu, 1990). In the past decades, the yield of $S$. taty has gradually increased, while the yield of traditional commercial fish, such as the yellow croaker, has declined (Xiong et al., 2009). The half-fin anchovy has become an important fishery protein source in China.

Considerable researches about $S$. taty have shown that the resources of half-fin anchovy have been destroyed because of overfishing in the East China Sea (Jiao et al., 2001) and the Yellow Sea (Xu et al., 2003) of China in recent years. As is well known, the half-fin anchovy plays an important role in the food chain. They eat zooplankton and are prey for larger fish (Sheng and Wei, 1992). Once the resource of half-fin anchovy is greatly destroyed, the ecological system would be affected and difficult to restore. Therefore, it is important to protect germplasm resource of half-fin anchovy and further study its genetic diversity.

To date, most of studies on $S$. taty are related to the ecological aspects of the species (Song et al., 2010, 2011), but little is known about its genetic characteristics. The study of genetic diversity can provide specific measures to protect the germplasm resource. Additionally, detailed analyses of the levels and spatial distribution of genetic diversity are vital to develop effective conservation and management for this species (Hedrick and Miller, 1992). Therefore, it is necessary to determine the level of genetic variation within and among populations of S. taty.

Development of molecular markers provides the repertoire for assessing genetic diversity at the DNA level in marine organisms (Reif et al., 2003). In particular, simple sequence repeat (SSR) markers are potential tools for large-scale DNA fingerprinting of $S$. taty genotypes because of their high level of polymorphism detected (Smith et al., 1997), automated analysis systems (Mitchell et al., 1997), and high accuracy and repeatability (Heckenberger et al., 2003). Nevertheless, the development and genetic diversity of SSR molecular markers within and among the populations of $S$. taty was not studied. To investigate the genetic characteristics of $S$. taty, we first developed polymorphic microsatellite markers using the fast isolation by amplified fragment length polymorphism of sequences containing repeats (FIASCO) method (Zane et al., 2002). Then, we used the markers for the next following research of genetic diversity and population structure.

The objective of our study is to assess the genetic diversity within populations and differentiation between populations of the half-fin anchovy from the East China Sea and the Yellow Sea using microsatellite markers that we developed. This research can make possible to identify genetically distinct populations within the species. In addition, we can analyze the hereditary constitution and use the results of this study to protect the germplasm resources of S. taty. 


\section{MATERIAL AND METHODS}

\section{Sample collection}

Based on geographic origin and ecotype, a total of 150 samples of $S$. taty were collected from five locations that could be divided into two geographic areas: the East China Sea, which contained three populations (Zhoushan, Ninghai and Xiangshan) and the Yellow Sea, which contained the other two populations (Yantai and Weihai) (Figure 1). Five samples per population were used to develop and characterize the SSR markers. Then, 30 wild individuals were selected per population for the genetic diversity and population structure study. The tissue samples were obtained from fin clips of $S$. taty and preserved in $95 \%$ ethanol, and finally stored at $-20^{\circ} \mathrm{C}$.

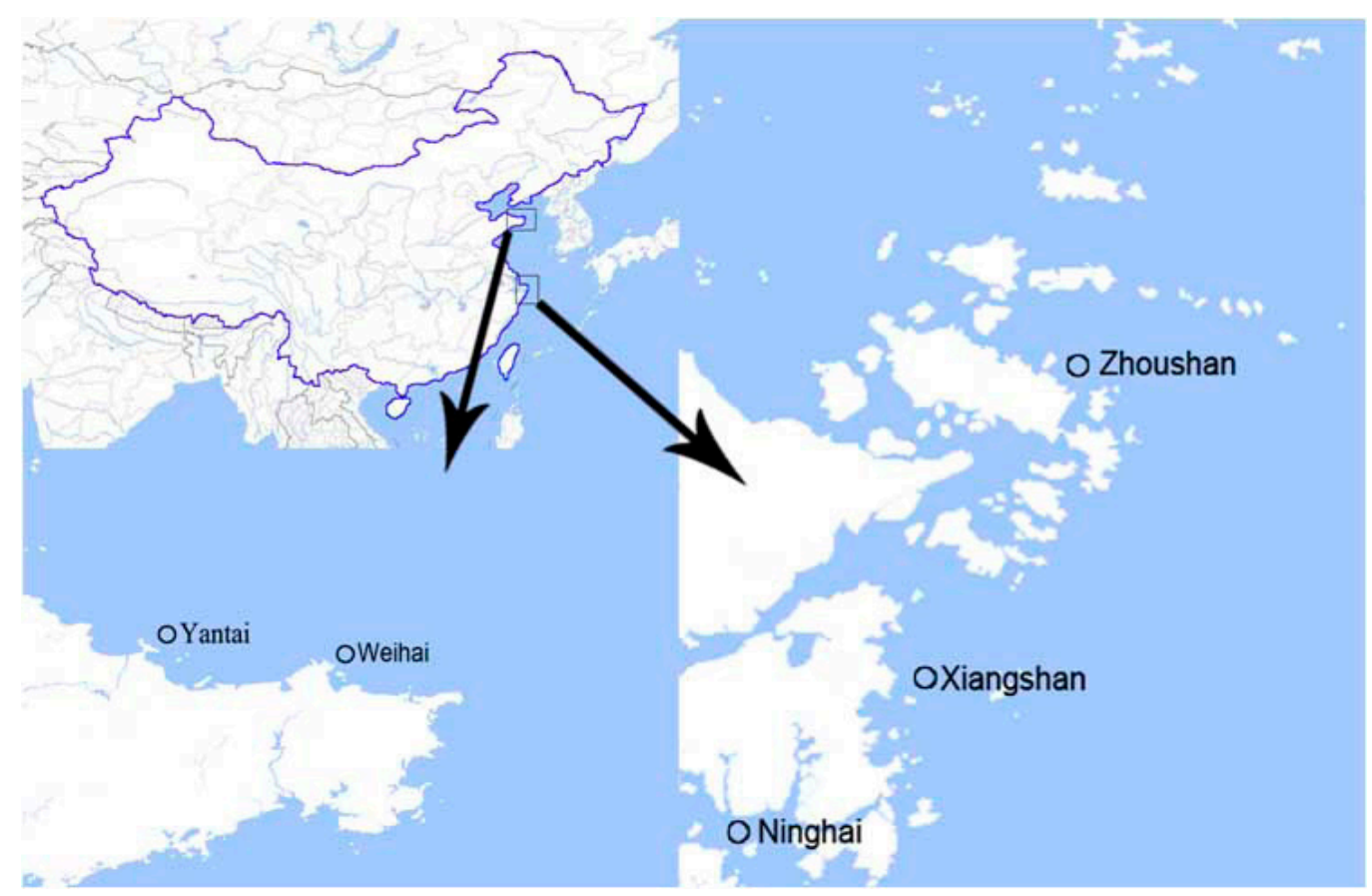

Figure 1. Sample sites for the half-fin anchovy.

\section{DNA extraction, microsatellite screening and SSR analysis}

Total DNA was extracted from 150 individuals using the standard phenol-chloroform method, with some modification. Microsatellite loci enriched from genomic libraries were constructed following the process of FIASCO method. Briefly, genomic DNA was digested using MseI restriction enzyme (NEB), and DNA fragments of approximately 200-1000 bp were purified, and ligated to adapters OligoA (5'-TACTCAGGACTCAT$\left.3^{\prime}\right)$ and OligoB (5'-GACGATGAGTCCTGAG-3'), and amplified using MseI-N (5'-GATGAGTCCTGAGTAAN-3'). The amplified products containing microsatellite sequences were captured by hybridizing with $(\mathrm{CA})_{15}$ biotin-labeled probes. The microsatellite 
enrichment was separated using streptavidin magnetic beads according to Glenn and Schable's methods (Glenn and Schable, 2005), with minor modifications. Finally, the separated fragments were cloned into the pMD19-T vectors (TaKaRa, Dalian, China) using ultra-competent Escherichia coli DH5a (Tiangen, Beijing, China). Positive clones were screened by polymerase chain reaction (PCR) with M13-F/M13-R and sequenced on an ABI 3730 automated sequencer. From the 60 sequenced clones, 54 (90\%) sequences contained microsatellites that had no less than seven dinucleotide repeats. A total of 33 pairs of primers were designed using the Primer Premier 5.0 software (Lalitha, 2000).

PCR amplifications were carried out in $15-\mu \mathrm{L}$ volumes, which contained $10 \mu \mathrm{L}$ sterilized water, $1.5 \mu \mathrm{L}$ 10X PCR buffer (containing $1.5 \mathrm{mM} \mathrm{Mg}^{2+}$ ), $1.2 \mu \mathrm{L} 2.5 \mathrm{mM}$ dNTPs, $0.6 \mu \mathrm{L}$ forward and reverse primers, $1 \mu \mathrm{L}$ diluted DNA template, and $0.1 \mu \mathrm{L} 5 \mathrm{U}$ Taq DNA polymerase (Tiangen). Thermal cycling conditions were implemented as follows: $94^{\circ} \mathrm{C}$ for 5 min, following by 30 cycles of $94^{\circ} \mathrm{C}$ for $40 \mathrm{~s}$, annealing temperature for $30 \mathrm{~s}$, and $72^{\circ} \mathrm{C}$ for 40 $\mathrm{s}$, followed by 1 cycle of $72^{\circ} \mathrm{C}$ for $5 \mathrm{~min}$ and then holding at $4^{\circ} \mathrm{C}$. PCR amplifications were performed on ABI 9700. Amplified products were denatured for 8 min at $96^{\circ} \mathrm{C}$ and separated on $6 \%$ denaturing polyacrylamide (19:1 acrylamide:bis-acrylamide) gels using silver staining. Denatured pBR322 DNA/MspI molecular weight marker (Tiangen) was used as the size standard to the lengths of PCR products to identify alleles.

\section{Data analysis}

The number of alleles per locus $\left(N_{\mathrm{A}}\right)$, expected heterozygosity $\left(H_{\mathrm{E}}\right)$, observed heterozygosity $\left(H_{\mathrm{O}}\right)$ and polymorphism information content (PIC) were estimated using the POPGENE software package (Yeh and Yang, 1997). Gene flow $\left(N_{\mathrm{m}}\right)$ and Shannon's indices $(I)$ were also calculated by the same software to characterize the genetic diversity and the distribution of the variation. An unbiased test of the exact test statistic was calculated using a Markov chain method (the Markov chain parameters used were 100,000 steps). All results for multiple tests were corrected using Bonferroni's correction (Rice, 1989).

A hierarchical analysis of molecular variance (AMOVA) (Excoffier et al., 1992) was performed using ARLEQUIN to calculate genotypic linkage disequilibrium between these loci and estimate how the variation was partitioned among populations. Based on Nei's standard genetic distance (Nei, 1972), a neighbor-joining (NJ) tree was constructed using the FigTree software. The population structure was determined using the Bayesian model-based clustering by implementing the STRUCTURE software (Evanno et al., 2005). Individuals were grouped into a predefined number of $K$ clusters $(2 \leq K \leq 9)$, with 100 independent runs for each value (Pritchard and Wen, 2004).

\section{RESULTS}

\section{Development and characterization of microsatellite markers}

The details of developing and characterizing microsatellite loci and variability measures across 30 individuals of the half-fin anchovy are summarized in Table 1. In total, 11 of 33 loci were successfully amplified and shown to be polymorphic. All 11 sequences containing microsatellite loci were deposited in GeneBank (accession Nos. JF502223-JF502233). $N_{\mathrm{A}}$ for each locus ranged from 2 to 10 , with an average of 5.273. $H_{\mathrm{E}}$ and $H_{\mathrm{O}}$ ranged from 0.124 to 0.861 and 
0.133 to 0.759 , respectively. The remaining 22 loci were monomorphic and failed to amplify. Three loci (Seta-33, Seta-56 and Seta-H79) significantly deviated from the Hardy-Weinberg equilibrium (HWE) in the sampled population after Bonferroni's correction, possibly because of the presence of null alleles. Null alleles were detected in five loci (Seta-33, Seta-56, Seta-79, Seta-H1, and Seta-H79) and stuttering errors were found in locus Seta-56, but no evidence of allelic dropout was found in any of the loci using MICRO-CHECKER (Van Oosterhout et al., 2004). According to pairwise tests, significant linkage disequilibrium was found between Seta79 and Seta-H23.

\begin{tabular}{|c|c|c|c|c|c|c|c|c|c|}
\hline Locus & GenBank & Primer sequence (5'-3') & $\operatorname{Tm}\left({ }^{\circ} \mathrm{C}\right)$ & Repeat motif & $\begin{array}{l}\text { Size range } \\
\text { (bp) }\end{array}$ & $N_{\mathrm{A}}$ & $\begin{array}{l}\text { HWE } \\
\text { (P) }\end{array}$ & Null & $H_{\mathrm{O}} / H_{\mathrm{E}}$ \\
\hline Seta-33 & JF502223 & $\begin{array}{l}\text { F: CTTGAGCGGCTATTGTTT } \\
\text { R: AGGGTGCTTGAGTTTATTTC }\end{array}$ & 52 & $(\mathrm{AC})_{7} \mathrm{G}(\mathrm{CA})_{6}$ & $199-227$ & 10 & $0.000^{*}$ & 1 & $0.571 / 0.832$ \\
\hline Seta-56 & JF502224 & $\begin{array}{l}\text { F: AACAGCCTAATTTCAATC } \\
\text { R: ATGCCATAGTCTCCTCAG }\end{array}$ & 52 & $(\mathrm{TG})_{12} \mathrm{CGTA}(\mathrm{TG})_{6}$ & $160-190$ & 7 & $0.000^{*}$ & 1 & $0.240 / 0.702$ \\
\hline Seta-79 & JF502225 & $\begin{array}{l}\text { F: TAACCCCAGCCCATTG } \\
\text { R: GCTAGACCTCCTCCAGTG }\end{array}$ & 52 & $(\mathrm{GT})_{8} \ldots(\mathrm{GT})_{11}$ & 188-194 & 2 & 0.007 & 1 & $0.240 / 0.499$ \\
\hline Seta-H1 & JF502226 & $\begin{array}{l}\text { F: ATGACCTGACCTGTAGATTAC } \\
\text { R: AGCCAATAAGCACTGAAGAT }\end{array}$ & 60 & $(\mathrm{TG})_{13}$ & $190-216$ & 9 & 0.005 & 1 & $0.567 / 0.861$ \\
\hline Seta-H8 & JF502227 & $\begin{array}{l}\text { F: AGCGATAACATTCTTGACTG } \\
\text { R: CAAACAGGACAACTGAAACT }\end{array}$ & 50 & $(\mathrm{TG})_{14}$ & $132-210$ & 7 & 0.440 & 0 & $0.600 / 0.708$ \\
\hline Seta-H23 & JF502228 & $\begin{array}{l}\text { F: AAGATCAACAGAGGCTGAC } \\
\text { R: CTCCGCTAATATCCACCAT }\end{array}$ & 50 & $(\mathrm{GT})_{11}$ & $143-149$ & 3 & 0.169 & 0 & $0.321 / 0.335$ \\
\hline Seta-H36 & JF502229 & $\begin{array}{l}\text { F: GTCATCTGCCTGGGTGAT } \\
\text { R: CAAGAACTGTGCCCTATGC }\end{array}$ & 58 & $(\mathrm{AC})_{8}$ & $118-122$ & 2 & 0.467 & 0 & $0.444 / 0.384$ \\
\hline Seta-H38 & JF502230 & $\begin{array}{l}\text { F: TAACCACAGGAGCAGTAC } \\
\text { R: CACTCACCAACAGTCACA }\end{array}$ & 58 & $(\mathrm{GT})_{6} \ldots(\mathrm{TG})_{9}$ & $120-122$ & 2 & 0.737 & 0 & $0.133 / 0.124$ \\
\hline Seta-H39 & JF502231 & $\begin{array}{l}\text { F: CTTAGATGGCTGGTGGATAT } \\
\text { R: AATTGTGTCAGACTTGTCAG }\end{array}$ & 55 & $(\mathrm{CA})_{9}$ & 233-261 & 6 & 0.047 & 0 & $0.759 / 0.807$ \\
\hline Seta-H79 & JF502232 & $\begin{array}{l}\text { F: CAGGTGTCACCACATTGT } \\
\text { R: CAGGAGTAGAGTAGAGGAGTA }\end{array}$ & 58 & $(\mathrm{TG})_{11} \ldots(\mathrm{TG})_{6}$ & 156-182 & 6 & $0.000^{*}$ & 1 & $0.241 / 0.680$ \\
\hline Seta-H94 & JF502233 & $\begin{array}{l}\text { F: TCCATCGGCTGTGTAGTC } \\
\text { R: TGAGACCCTCTTTCTGACA }\end{array}$ & 55 & $(\mathrm{CA})_{25}$ & 176-184 & 4 & 0.018 & 0 & $0.400 / 0.593$ \\
\hline
\end{tabular}

*Significant deviation from Hardy-Weinberg equilibrium.

\section{Genetic diversity and population structure}

The 11 polymorphic microsatellite loci developed in $S$. taty were used in studies of the genetic variation and population structure. The genetic information for loci is summarized in Table 2. A total of 59 alleles were detected, and the mean numbers of alleles per locus was 5.36. All of the 11 loci detected possessed a high level of polymorphism, with the effective number of alleles per locus $\left(N_{\mathrm{F}}\right)$ ranging from 1.99 at Seta-H38 to 8.51 at Seta-H39.

Genetic diversity parameters for each population, based on allelic frequencies, are presented in Table 3. $N_{\mathrm{E}}$ varied from 3.182 to 4.429 , with an average of 3.763. $H_{\mathrm{O}}$ ranged from 0.384 to 0.620 , with an average of $0.484 . H_{\mathrm{E}}$ was slightly higher than $H_{\mathrm{O}}$, ranging from 0.600 to 0.730 , with a mean value of 0.664 . The average $I$ was 1.295 at the population level. We did not observe significant departures from HWE at most loci and in most of the populations sampled nor did we find consistent departure patterns across the loci and populations (Table 4). The significant deviations from HWE in the case of 3 loci (Seta-33, Seta-H1 and Seta-H79) in the Yantai population might be because of the presence of null alleles. 
Table 2. Relative measurements on expected heterozygosity $\left(H_{\mathrm{E}}\right)$, observed heterozygosity $\left(H_{\mathrm{O}}\right)$, observed number of alleles $\left(N_{\mathrm{A}}\right)$, effective number of alleles $\left(N_{\mathrm{E}}\right)$, gene flow $\left(N_{\mathrm{m}}\right)$, and polymorphism information content (PIC) among populations of Setipinna taty.

\begin{tabular}{|c|c|c|c|c|c|c|c|}
\hline Locus & $H_{\mathrm{o}}$ & $H_{\mathrm{E}}$ & $F_{\mathrm{ST}}$ & $N_{\mathrm{A}}$ & $N_{\mathrm{E}}$ & $N_{\mathrm{m}}$ & PIC \\
\hline Seta-H36 & 0.38 & 0.64 & 0.23 & 3 & 2.74 & 0.83 & 0.5602 \\
\hline Seta-H38 & 0.27 & 0.50 & 0.27 & 2 & 1.99 & 0.66 & 0.3736 \\
\hline Seta-H39 & 0.73 & 0.89 & 0.05 & 10 & 8.51 & 5.23 & 0.8690 \\
\hline Seta-H1 & 0.62 & 0.88 & 0.04 & 10 & 8.39 & 5.98 & 0.8711 \\
\hline Seta-H23 & 0.38 & 0.59 & 0.21 & 3 & 2.40 & 0.96 & 0.5141 \\
\hline Seta-H94 & 0.40 & 0.67 & 0.06 & 4 & 3.04 & 3.75 & 0.6085 \\
\hline Seta-33 & 0.47 & 0.85 & 0.04 & 7 & 6.40 & 5.82 & 0.8238 \\
\hline Seta-79 & 0.27 & 0.50 & 0.01 & 2 & 2.00 & 29.93 & 0.3744 \\
\hline Seta-H8 & 0.70 & 0.77 & 0.02 & 5 & 4.38 & 17.56 & 0.7338 \\
\hline Seta-56 & 0.59 & 0.80 & 0.06 & 6 & 5.04 & 4.29 & 0.7727 \\
\hline Seta-H79 & 0.52 & 0.75 & 0.03 & 7 & 3.96 & 7.56 & 0.7107 \\
\hline Mean & 0.49 & 0.71 & 0.08 & 5.36 & 4.44 & 2.81 & 0.6556 \\
\hline
\end{tabular}

Table 3. Details on effective number of alleles $\left(N_{\mathrm{E}}\right)$ per population, observed heterozygosity $\left(H_{\mathrm{O}}\right)$, expected heterozygosity $\left(H_{\mathrm{E}}\right)$, and Shannon's information index $(I)$ of genetic variation within populations of Setipinna taty based on eleven SSR loci.

\begin{tabular}{lcccc}
\hline Population & $N_{\mathrm{E}}$ & $H_{\mathrm{O}}$ & $H_{\mathrm{E}}$ & $I$ \\
\hline Zhoushan & 3.182 & 0.446 & 0.628 & 1.186 \\
Ninghai & 3.473 & 0.384 & 0.600 & 1.214 \\
Yantai & 4.429 & 0.620 & 0.730 & 1.434 \\
Weihai & 4.013 & 0.552 & 0.712 & 1.384 \\
Xiangshan & 3.718 & 0.417 & 0.648 & 1.256 \\
\hline
\end{tabular}

\begin{tabular}{|c|c|c|c|c|c|c|c|c|c|c|c|c|}
\hline Population & Parameter & Seta-H36 & Seta-H38 & Seta-H39 & Seta-H1 & Seta-H23 & Seta-H94 & Seta- 33 & Seta-79 & Seta-H8 & Seta-56 & Seta-H79 \\
\hline \multirow[t]{2}{*}{ Zhoushan } & $\mathrm{f}$ & -0.1254 & -0.2250 & 0.0016 & 0.5330 & 0.2641 & 0.6908 & 0.3727 & 0.3993 & -0.1846 & 0.2814 & 0.6433 \\
\hline & $H_{\mathrm{E}}$ & 0.2488 & 0.4082 & 0.7598 & 0.8412 & 0.4853 & 0.6220 & 0.7675 & 0.4994 & 0.7503 & 0.6958 & 0.7009 \\
\hline \multirow[t]{2}{*}{ Ninghai } & $\mathrm{f}$ & 0.8014 & 0.8383 & 0.5193 & 0.1344 & 0.3412 & 0.3898 & 0.6468 & 0.4570 & -0.0225 & 0.2095 & 0.1283 \\
\hline & $H_{\mathrm{E}}$ & 0.3472 & 0.2061 & 0.8609 & 0.8472 & 0.1626 & 0.5673 & 0.7928 & 0.4911 & 0.7606 & 0.7497 & 0.6883 \\
\hline \multirow[t]{2}{*}{ Yantai } & $\mathrm{f}^{\mathrm{E}}$ & 0.0947 & 0.2457 & -0.0119 & -0.0902 & 0.0840 & 0.2195 & 0.1994 & 0.6571 & 0.0491 & 0.2562 & 0.0418 \\
\hline & $H_{\mathrm{E}}$ & 0.6628 & 0.4861 & 0.8894 & 0.8561 & 0.6550 & 0.7321 & 0.8476 & 0.4861 & 0.7361 & 0.8067 & 0.7306 \\
\hline \multirow[t]{2}{*}{ Weihai } & $\mathrm{f}^{\mathrm{f}}$ & 0.4426 & 0.0834 & -0.0811 & 0.3792 & -0.0415 & 0.2246 & 0.4225 & 0.3993 & 0.0850 & 0.1441 & 0.2771 \\
\hline & $H_{\mathrm{E}}$ & 0.6578 & 0.4728 & 0.8633 & 0.8055 & 0.5761 & 0.6687 & 0.8359 & 0.4994 & 0.7650 & 0.7789 & 0.7839 \\
\hline \multirow[t]{2}{*}{ Xiangshan } & $\mathrm{f}^{\mathrm{f}}$ & -0.1309 & 0.7115 & 0.2463 & 0.3891 & 0.5220 & 0.3803 & 0.4897 & 0.3304 & 0.4866 & 0.1959 & 0.3493 \\
\hline & $H_{\mathrm{E}}$ & 0.5240 & 0.2311 & 0.8354 & 0.8769 & 0.4184 & 0.5565 & 0.7984 & 0.4978 & 0.7936 & 0.7551 & 0.7093 \\
\hline
\end{tabular}

For the five populations, the average PIC per locus ranged from 0.3736 to 0.8711 (Table 2), of which, four loci indicated middle polymorphism $(0.25<\mathrm{PIC}<0.5)$, while the other seven loci were all high polymorphism (PIC $>0.5$ ) (Shete et al., 2000). The genetic variations between populations were estimated using the Wright's theory of hierarchical $F$-statistics $\left(F_{\mathrm{ST}}\right)$ (Wright, 1965). Values of $F_{\mathrm{ST}}$ ranged from 0.01 at locus Seta-79 to 0.27 at locus Seta-H38, with an average value of 0.08 (Table 2). This suggested that this species exhibited most of its genetic variation within its population.

Significant genetic heterogeneity among the five populations was indicated by AMOVA (Table 5). The fixation index $\left(F_{\mathrm{ST}}\right)$ was 0.068 . AMOVA suggested that genetic variation mainly occurred within individuals $(70.68 \%)$, while that among individuals within populations and 
among populations was 22.47 and $6.85 \%$, respectively. The genetic distances among the five populations had overt differences, and they ranged from 0.0468 between Yantai and Weihai to 0.3972 between Yantai and Zhoushan (Table 6). On the basis of the inter-population genetic distance, an NJ tree was constructed (Figure 2). The samples from Zhoushan, Ninghai, and Xiangshan locations were segmented into one cluster, while the other two populations were divided into the other cluster. In conclusion, among different populations, the samples not only could be distinguished from each other but also could be easily separated between the two sea areas, the East China Sea and the Yellow Sea.

Table 5. Analysis of molecular variance among and within the five populations.

\begin{tabular}{lcccc}
\hline Source of variation & Variation components & Percentage of variation & F statistic & P \\
\hline Among populations & 0.1124 & 6.85 & 0.0685 & $\mathrm{P}<0.001$ \\
Within populations & 0.3688 & 22.47 & 0.2412 & $\mathrm{P}<0.001$ \\
Within individuals & 1.1600 & 70.68 & 0.2932 & $\mathrm{P}<0.001$ \\
\hline
\end{tabular}

\begin{tabular}{|c|c|c|c|c|c|}
\hline & Zhoushan & Ninghai & Yantai & Weihai & Xiangshan \\
\hline Zhoushan & & 0.6722 & 0.8172 & 0.7748 & 0.7032 \\
\hline Ninghai & 0.2018 & & 0.8625 & 0.8206 & 0.8011 \\
\hline Yantai & 0.3972 & 0.2218 & & 0.9543 & 0.8626 \\
\hline Weihai & 0.3522 & 0.1977 & 0.0468 & & 0.9022 \\
\hline Xiangshan & 0.2552 & 0.1479 & 0.1484 & 0.1029 & \\
\hline
\end{tabular}

Below diagonal is the genetic distance and above diagonal is the genetic identity.

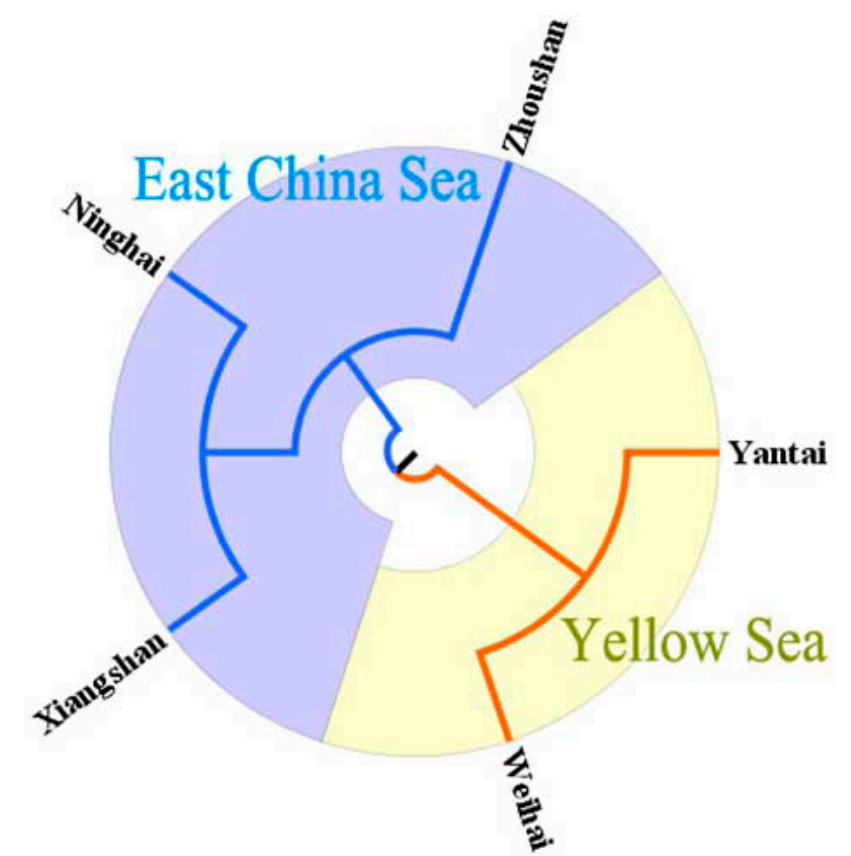

Figure 2. Neighbor-joining tree analysis based on Nei's genetic distance among five populations of Setipinna taty. 
The results of the structure analysis as $\mathrm{K}=2$ are shown in Figure 3. We used the $\mathrm{K}$ values from two to seven to perform a calculation for the cluster analysis, and we found that when the $\mathrm{K}$ value was 2, the five populations were divided into two clusters. This result was consistent with the geographical distribution of the 5 populations: the half-fin anchovy from Zhoushan, Ninghai and Xiangshan belonged to the East China Sea, and those from Yantai and Weihai pertained to the Yellow Sea. Using the method developed by Evanno et al. (2005), we also identified two clusters as the most probable solution.

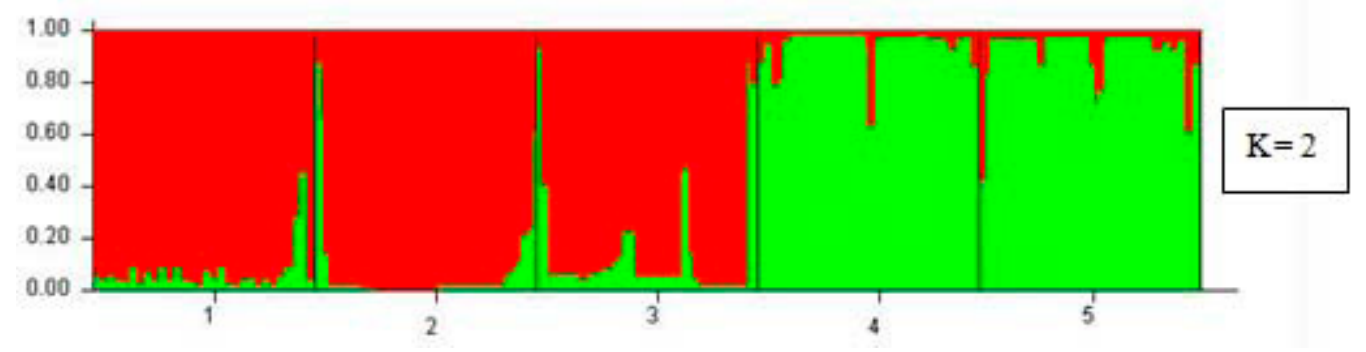

Figure 3. Substructure of five Setipinna taty populations from the East China Sea and the Yellow Sea. 1, 2, 3, 4, 5 stand, respectively, for Ninghai, Xiangshan, Zhoushan, Yantai, and Weihai.

\section{DISCUSSION}

In this report, we detected that the value of $H_{\mathrm{E}}(0.71)$ at the population level could indicate the genetic diversity; this result suggest that the degree of DNA polymorphism and the genetic diversity in this species were very high. In addition, our study showed that genetic analysis based on allelic and genotypic frequencies according to the heterozygosity excess test was much better than the heterozygosity excess test only. Additionally, the average value of the PIC (0.656) also indicated the high genetic diversity in S. taty.

Generally deviation from HWE was due to the heterozygosity excess, which was followed in our study at most of the 11 loci in the five populations. Selection, population mixing, and nonrandom mating could be employed to account for the deviation from HWE. The high average $N_{\mathrm{E}}$ in the population suggested that the genetic variation condition was good, while a population with less genetic differentiation should receive more attention and enhanced protection. The populations of Weihai and Yantai had higher average $N_{\mathrm{E}}$ values than the other three populations. We should pay more attention to the populations of Zhoushan, Ninghai and Xiangshan because the low $N_{\mathrm{E}}$ indicated that they had low evolution ability.

Based on the Nei's genetic distance, the NJ tree analysis indicated that the samples from Zhoushan, Ninghai, and Xiangshan locations were obviously separated from the other two populations (Yantai and Weihai). This showed that the populations of Zhoushan, Ninghai, and Xiangshan, which came from the East China Sea, had their own unique evolutionary pathways that were unlike the other two populations from the Yellow Sea. This result indicated that high genetic diversity existed in two different geographic populations of $S$. taty species.

When the $\mathrm{K}$ value was 2 , the five populations were divided into two clusters: the three populations of Zhoushan, Ninghai and Xiangshan clustered and were separated from the other two populations, indicating that the East China Sea populations made up a gene pool that was 
different from that of the two populations from the Yellow Sea. The graph indicated that the geographic isolation affected the evolution of the population directly, so they had their own gene pool and became two subspecies.

The genetic data obtained from $S$. taty based on microsatellite markers indirectly reflected the adaptive genetic diversity. Low levels of genetic diversity at loci might reflect the losses of genetic diversity that could influence the fitness. Preserving variation might help to inhibit the dissolution of locally well-adapted phenotypes (Godt et al., 1996; Ueno et al., 2005; Jones and Gibson, 2011). It is important to note that a species should be maintained within its ecological community, and more genetic diversity research related to adaptive traits and the knowledge about ecosystem functions and species interactions would be helpful to understand how the species could adapt to changing conditions.

In summary, we first developed microsatellite markers for $S$. taty and used them in population genetic studies of this species. The isolation of the SSR markers provided the material for the analysis of genetic diversity and population structure. All of the indexes in our research indicated that high genetic diversity existed in different geographic populations of $S$. taty. five populations from two geographical regions had high genetic variations, which could be used to the further protection of the resources of this species.

\title{
ACKNOWLEDGMENTS
}

\author{
Research supported by the Zhejiang Provincial Natural Science Foundation \\ (\#LY13C040001).
}

\section{REFERENCES}

Evanno G, Regnaut S and Goudet J (2005). Detecting the number of clusters of individuals using the software STRUCTURE: a simulation study. Mol. Ecol. 14: 2611-2620.

Excoffier L, Smouse PE and Quattro JM (1992). Analysis of molecular variance inferred from metric distances among DNA haplotypes: application to human mitochondrial DNA restriction data. Genetics 131: 479-491.

Glenn TC and Schable NA (2005). Isolating microsatellite DNA loci. Methods Enzymol. 395: 202-222.

Godt MJW, Johnson BR and Hamrick JL (1996). Genetic diversity and population size in four rare Southern Appalachian plant species. Conserv. Biol. 10: 796-805.

Gu H (1990). Feeding habits and food composition of half-fin anchovy, Setipinna taty (C et V) in the Bohai Sea. Chin. J. Oceanol. Limnol. 8: 280-288.

Heckenberger M, van der Voort JR, Peleman J and Bohn M (2003). Variation of DNA fingerprints among accessions within maize inbred lines and implications for identification of essentially derived varieties: II. Genetic and technical sources of variation in AFLP data and comparison with SSR data. Mol. Breed. 13: 97-106.

Hedrick PW and Miller PS (1992). Conservation genetics: techniques and fundamentals. Eco. Appl. 2: 30-46.

Jiao Y, Chen DG, Liu Q and Zhong CJ (2001). Biological characteristics of some small species in Engraulidae and Clupeidae. J. Fish. China 25: 323-329.

Jones J and Gibson J (2011). Population genetic diversity and structure within and among disjunct populations of Alnus maritima (seasidealder) using microsatellites. Conserv. Genet. 12: 1003-1013.

Lalitha S (2000). Primer Premier 5. Biotechnol. Software Internet Rep. 1: 270-272.

Mitchell SE, Kresovich S, Jester CA and Hernandezc J (1997). Application of multiplex PCR and fluorescence-based, semi-automated allele sizing technology for genotyping plant genetic resources. Crop Sci. 37: 617-624.

Nei M (1972). Genetic distance between populations. Am. Natur. 106: 283-292.

Pritchard JK and Wen W (2004). Documentation for STRUCTURE software: version 2. Department of Human Genetics, University of Chicago, Chicago.

Reif J, Melchinger A, Xia XC and Warburton ML (2003). Genetic distance based on simple sequence repeats and heterosis in tropical maize populations. Crop Sci. 43: 1275-1282. 
Rice WR (1989). Analyzing tables of statistical tests. Evolution 43: 223-225.

Sheng W and Wei J (1992). Study on food web of fishes in the Yellow Sea. Ocean. Et. Limn. Sin. 23: 182-192.

Shete S, Tiwari H and Elston RC (2000). On estimating the heterozygosity and polymorphism information content value. Theor. Popul. Biol. 57: 265-271.

Smith JSC, Chin ECL, Shu H and Smith OS (1997). An evaluation of the utility of SSR loci as molecular markers in maize (Zea mays L.): comparisons with data from RFLPs and pedigree. Theor. Pop. Bio. 95: 163-173.

Song R, Wei RB, Xie C and Wang DF (2010). Antibacterial activity and stability of half-fin anchovy (Setipinna taty) protein hydrolysate. Food Sci. 31: 88-92.

Song R, Wei R, Zhang B, Yang Z, et al. (2011). Antioxidant and antiproliferative activities of heated sterilized pepsin hydrolysate derived from half-fin anchovy (Setipinna taty). Mar. Drugs 9: 1142-1156.

Ueno S, Setsuko S, Kawahara T and Yoshimaru H (2005). Genetic diversity and differentiation of the endangered Japanese endemic tree Magnolia stellata using nuclear and chloroplast microsatellite markers. Conserv. Genet. 6: 563-574.

Van Oosterhout C, Hutchinson WF, Wills DPM and Shipley P (2004). MICRO-CHECKER: software for identifying and correcting genotyping errors in microsatellite data. Mol. Ecol. Notes 4: 535-538.

Wright S (1965). The interpretation of population structure by F-statistics with special regard to systems of mating. Evolution 19: 395-420.

Xiong Y, Tang JH, Li PY and Zhong XM (2009). Resource estimate on Setipinna taty in the southern Yellow Sea. Chin. J. Ocean. Limn. 40: 500-505.

$\mathrm{Xu} \mathrm{BD}$, Jin XS and Liang L (2003). Changes of demersal fish community structure in the Yellow Sea during the autumn. J. Fish. Sci. China 10: 148-154.

Yeh F and Yang R (1997). POPGENE, the User-Friendly Shareware for Population Genetic Analysis. Molecular Biology and Biotechnology Centre, University of Alberta, Edmonton.

Zane L, Bargelloni L and Patarnello T (2002). Strategies for microsatellite isolation: a review. Mol. Ecol. 11: 1-16. 